\title{
Bitcoin Piyasasında Haftanın Günü Anomalisi
} (Araştırma Makalesi)

\author{
The Day of the Week Anomaly in Bitcoin Market
}

Doi: 10.29023/alanyaakademik.664776

\section{Samet EVCI}

Dr. Ögrr. Üyesi, Osmaniye Korkut Ata Üniversitesi, İktisadi ve İdari Bilimler Fakültesi, sametevci@osmaniye.edu.tr

Orcid No: 0000-0002-5854-3847

Bu makaleye atıfta bulunmak için: Evci, S. (2020). Bitcoin Piyasasında Haftanın Günü Anomalisi.. Alanya Akademik Bakış, 4(1), Sayfa No. 53-61.

Anahtar kelimeler:
Bitcoin, haftanın
günü etkisi, anomali,
etkin piyasa hipotezi
Makale Geliş Tarihi:
25.12.2019
Kabul Tarihi:
22.01.2020

Keywords:

Bitcoin, day of the week effect, anomaly, effective market hypothesis

\section{ÖZET}

Kripto para piyasası kısa dönemde çok hızlı bir gelişim göstermiş hem yatırımcıların hem de akademisyenlerin ilgisini çekmiştir. Bu piyasada en fazla piyasa değerine sahip kripto para birimi Bitcoin'dir. Gerek geleneksel finansal piyasaların işleyiş̧inden farklı bir piyasa işleyiş̧ine sahip olması gerekse para yaratma sürecinde farklı bir sistemi kullanması yatırımcılar açısından Bitcoin fiyatlarında değişime yol açan faktörleri anlamayı gerekli kllmaktadır. Bu çalışma ile Bitcoin fiyatlarında haftanın günü anomalisinin varlığının araştırılması amaçlanmıştır. Bitcoin getirilerinde haftanın günü anomalisi, 2013-2019 yillarına ait günlük fiyatlar kullanılarak asimetrik GARCH modeliyle incelenmiştir. Çalışmadan elde edilen bulgular Bitcoin getirileri üzerinde Pazartesi, Perşembe ve Pazar günlerinin negatif etkileri olduğunu ve en fazla kaybın Perşembe günü gerçekleştiğini ortaya koymuştur.

\begin{abstract}
The cryptocurrency market has developed very rapidly in the short term and attracted the attention of both investors and academicians. Bitcoin has the highest market capitalization in cryptocurrency market. Because Bitcoin has a different market operation than traditional financial markets and uses a different system in the process of creating money, investors need to understand the factors that lead to changes in Bitcoin prices. The aim of this study is to investigate the presence of anomaly in the day of the week in Bitcoin prices. Day-of-week anomaly in Bitcoin returns was analyzed using asymmetric GARCH model using daily prices for 2013-2019. The findings of the study revealed that Monday, Thursday and Sunday had negative effects on Bitcoin returns and the maximum loss occurred on Thursday.
\end{abstract}

\section{GİRIŞ}

Kripto para piyasası kısa dönemde çok hızlı bir gelişim göstermiştir. Öncü kripto para birimi Bitcoin'in Ocak 2009'da halka açılmasından bu yana, çoğunluğu yalnızca bir katsayı olan 550'den fazla şifreli para birimi geliştirilmiştir (Farell, 2015). Geleneksel ödeme araçlarına 
göre kripto para birimlerinde, transfer işlemlerinde ücret ve komisyonların olmaması, işlemlerin zaman ve mekan sınırlaması olmadan hızlı gerçekleşmesi, herhangi bir düzenleyici otoriteye tabi olmaması, fiyat değişimlerinden sağlanan yüksek kazançlar gibi sağladığ avantajlar kripto para birimlerinin yaygınlaşmasında etkili olmuş ve kripto para piyasası yaklaşık 240 milyar dolar büyüklüğe ulaşmıştır (Tradingview, 2019).

Kripto para piyasasında, yaklaşı \%66 oranla en fazla piyasa değerine sahip kripto para birimi Bitcoin'dir (Coinmarketcap, 20119). Bitcoin, para birimlerinin oluşturulmasında ve dağıtımında kriptoptagrafiyi kullanan noktadan noktaya (peer to peer, P2P) bir işlem sistemidir (Mukhopadhyay vd., 2016). Sistem, Satoshi Nakamoto takma adiyla 2008 yılında yayımlanan "Bitcoin: Peer to Peer Electronic Cash System" başlıklı çalışmayla uygulamaya konulmuştur (Koçoğlu vd., 2016: 79). Bu sistemde para transferleri bir noktadan bir noktaya hızlı bir şekilde gerçekleşmekte ve hangi hesaba transfer yapıldığı kayıt altına alınmaktadır (Gültekin ve Bulut, 2016: 84). Para transferlerine ilişkin tüm kayitlar blok zinciri olarak bilinen açık deftere kaydedilmektedir. Bu kayıtlar blok zincirinde saklanmakta ve ağdaki tüm bilgisayarlarla paylaşılmaktadır (Jang ve Lee, 2018). Ağdaki bilgisayarlarla paylaşılan ve doğrulanan her işlem blok zincirinde yer alan bir blokta toplanmaktadır. Tamamlanan blokların eklenmesiyle blok sürekli büyümekte ve blok zinciri oluşmaktadır (Mukhopadhyay vd., 2016).

Bitcoin piyasasının işleyişi, geleneksel finansal piyasaların işleyişinden farklıdır. Bu durum hem akademisyenlerin hem de yatırımcıların ilgisini çekmiş ve Bitcoin piyasasını inceleyen akademik çalışmaların sayısının artmasını sağlamıştır. Bu çalışmaların temel dayanağını Bitcoin piyasasındaki fiyat hareketleri oluşturmuştur (Fink ve Johann, 2014; Kristoufek, 2015; Osterrieder ve Lorenz, 2017; Jiang, Ruan ve Nie 2018; Lahmiri, Bekiros ve Salvi, 2018; Bariviera, Basgall, Hasperue ve Naiouf, 2017; Shi Sun, Gao, Xu, Shen ve Cheng, 2019). Finansal piyasalardaki fiyat hareketleri, o piyasayı anlamak, modellemek ve riski ölçmek için kilit rol oynamaktadır (Bouchaud ve Potters, 2003). Bunun yanı sıra Bitcoin'in, bir değişim aracı, riskten korunma aracı ve altın gibi değer saklama aracı olarak kullanılabilecek bir para birimi haline gelmesi durumunda; görece yeni bir fin-teknoloji aracının dinamiklerini ve davranışlarını anlamak önemli olacaktır (Aharon ve Qadan, 2019: 1). Bu bağlamda, bu çalışma ile Bitcoin fiyatlarında haftanın günü anomalisinin varlığının araştııılması amaçlanmaktadır. Çalışmanın, Bitcoin fiyatlarında takvim etkisinin var olup olmadığını ortaya koyarak, yatıımııının kararlarına yön vermesi, piyasada ortaya çıkan riski yönetmesine katkı sağlaması ve bu piyasada Etkin Piyasalar Hipotezinin geçerliliğini sorgulayarak literatüre katkı sağlaması beklenmektedir.

Çalışmanın takip eden bölümlerinde ilk olarak kripto para piyasasında haftanın günü etkisini inceleyen çalışmalara yer verilmiştir. Daha sonra çalışmada kullanılan veri seti ve yöntem açıklanmış ve son olarak elde edilen bulgular değerlendirilmiştir.

\section{LITERATÜR}

Fama (1970) tarafindan ortaya konulan Etkin Piyasalar Hipotezine göre fiyatların tüm bilgiyi yansittığ 1 piyasalar etkin olarak kabul edilmektedir. Etkin piyasalar hipotezi Rassal Yürüyüş Modeline dayanmaktadır. Model, geçmiş dönem fiyat hareketlerinden yararlanarak gelecek dönem fiyat hareketlerinin tahmin edilemeyeceğini ve fiyatların rassal olduğunu ifade etmektedir (Fama, 1965). Fama (1970), fiyatların rassal olduğunu ifade etse de literatürde, Etkin Piyasalar Hipotezinden sapan fiyat oluşumlarının gözlemlendiğini savunan çalışmalar 
yer almaktadır (Frenberg ve Hansson 1993; Smith ve Ryoo, 2012; Worthington ve Higgs 2003). Normalden sapan bu gözlemler anomali olarak tanımlanmaktadır. Haftanın günü etkisi de dönemsel anomaliler arasında yer almaktadır. Dönemsel anomaliler, finansal araçların getirisinin bazı gün, hafta, ay ve tatillerde diğer zamanlara göre daha yüksek ya da daha düşük olmasını ifade etmektedir (Arı ve Yüksel, 2017: 78).

Literatürde gerek pay piyasasında (Aggarwal ve Rivoli, 1989; Brooks ve Persand, 2001; Rodriguez, 2012) gerekse döviz piyasasında (Yamori ve Kurihara, 2004; Kurihara, 2011; Popovic ve Đurovic, 2014; Kumar, 2016) Etkin Piyasalar Hipotezinden sapmalara neden olan dönemsel anomalileri konu alan çok sayıda çalışma yer almaktadır. Fakat dönemsel anomalilerin Bitcoin piyasasındaki etkilerini inceleyen çalışmalar sınırlı sayıdadır. $\mathrm{Bu}$ çalışmalardan biri Kurihara ve Fukushima (2017) tarafından yapılmıştır. Çalışmalarında, Bitcoin piyasasında 2010-2016 yılları arasında haftanın günü anomalisini incelemişler ve piyasanın etkin olmadığı; hafta sonlarında fiyat anomalisinin gözlemlendiği bulgusuna ulaşmışlardır. Caporale ve Plastun (2017) çalışmalarında ortalama analiz, student t-testi, ANOVA, Kruskal-Wallis testi, kukla değişkenlerle regresyon analizi gibi istatistiksel teknikler ve simülasyon yöntemi kullanarak kripto para piyasasında haftanın günü etkisini incelemişlerdir. Çalışma sonunda, Bitcoin dışındaki çoğu para birimlerinde (LiteCoin, Ripple, Dash) haftanın günü anomalisinin gözlemlenmediği bulgusuna ulaşılmıştır. Bitcoin'de ise diğer günlere göre Pazartesi gününde getirilerin daha yüksek olduğu gözlemlenmiştir. Eyüboğlu (2018), Bitcoin ve Litecoin kripto para birimlerinde haftanın günü ve yılın ayın etkilerini incelemiştir. 2013-2017 yıllarına ait veri setinin kullanıldığı çalışmada, GARCH $(1,1)$ modeli kurularak analiz yapılmıştır. Analiz sonuçları, Bitcoin fiyatları üzerinde Pazartesi, Salı ve Cuma günlerinin; Litecoin fiyatlarında ise Cumartesi gününün etkili olduğunu ortaya koymuştur. Bunun yanı sıra Bitcoin fiyatları üzerinde Şubat, Ekim ve Kasım ayı etkisi ortaya çıkarken, Litecoin fiyatlarında Ağustos ayının etkili olduğu gözlemlenmiştir. Aharon ve Qadan (2019) çalışmalarında, 2010-2017 yıllarına ait günlük veriler kullanılarak, Bitcoin getirilerinde ve oynaklığında En Küçük Kareler Yöntemi ve GARCH modelleri ile haftanın günü etkisini incelemişlerdir. Çalışmanın bulguları, haftanın günü anomalisinin sadece Bitcoin getirilerinin yanı sıra Bitcoin oynaklığında da gözlemlendiğini ortaya koymuştur.

Konuya ilişkin sınırlı sayıdaki literatür genel olarak değerlendirildiğinde; Bitcoin piyasasının etkin olmadığını ve haftanın günü anomalisinin varlığını göstermiştir.

\section{VERİ SETII VE YÖNTEM}

Çalışmada Bitcoin piyasasında haftanın günü etkisini incelemek için 28.04.2013-22.11.2019 tarihleri arasındaki günlük fiyatlar kullanılmıştır. Bitcoin fiyatları coinmarketcap.com sitesinden temin edilmiştir.

Çalışmada ilk olarak günlük fiyat serilerinin doğal logaritmik getirileri hesaplanmış ve aşağıdaki eşitlik kullanılmıştır.

$$
\mathrm{Rt}=\operatorname{In}\left(\frac{\mathrm{P}_{\mathrm{t}}}{\mathrm{P}_{\mathrm{t}-1}}\right)
$$

Yukarıda eşitlikte Rt, Bitcoin'in t dönemindeki getirisini, InPt ve InPt-1 sırasıyla Bitcoin'in t ve t-1 dönemindeki doğal logaritmik fiyatını ifade etmektedir. 
Bitcoin getirileri üzerinde haftanın günü anomalisi, kukla değişkenlerin kullanıldığı aşağıdaki doğrusal regresyon denklemi üzerinden incelenmiştir.

$$
\mathrm{R}_{\mathrm{t}}=\beta_{1}+\sum_{\mathrm{i}=2}^{7} \beta_{\mathrm{i}} \mathrm{D}_{\mathrm{it}}+\varepsilon_{\mathrm{t}}
$$

Yukarıdaki eşitlikte, Rt, Bitcoin'in $\mathrm{t}$ dönemindeki logaritmik getirisini; Dit, haftanın günlerine ilişkin kukla değişkeni; $\beta$, haftanın her bir günü için ortalama getiriyi; $\varepsilon t$ ise sıfır ortalamalı ve sabit varyanslı hata terimini ifade etmektedir.

Regresyon denkleminde haftanın bir gününe ilişkin ortalama getiri sabit terimle $(\beta 1)$ ifade edilmekte, diğer günler için kukla değişkenler (Dit) tanımlanmaktadır. Kukla değişkenler, sabit terimle ifade edilen günün ortalama getirisinden diğer günlerin ortalama getirisinin sapmasını göstermektedir. Kukla değişken, o güne karşılık gelen gözlemler için 1 değerini, diğer gözlemler için 0 değerini almaktadır. Kukla değişkenlerin katsayılarının büyüklüğü, işareti ve istatistiksel olarak anlamlı olması anomaliler hakkında bilgi sağlamaktadır (Caporale ve Plastun, 2017: 260). Bu bağlamda modele ilişkin boş hipotez günlerin ortalama getirilerinin eşit olduğu şeklinde kurulurken $(\mathrm{Ho}=\beta 1=\beta 2=\beta 3=\beta 4=\beta 5=\beta 6=\beta 7)$, alternatif hipotez günlerin ortalama getirileri arasında farklılık olduğu $(H 1=\beta 1 \neq \beta 2 \neq \beta 3 \neq \beta 4 \neq \beta 5 \neq$ $\beta 6 \neq \beta 7)$ ve haftanın günü etkisinin olduğu şeklinde oluşturulmuştur. Kukla değişkenlerin katsayılarının istatistiki açıdan anlamlı olması durumunda boş hipotez reddedilmekte ve haftanın günü etkisinin olduğu sonucuna varılmaktadır.

$\mathrm{Bu}$ yöntemin kullanılması sırasında iki sorun ortaya çıkmaktadır. Birincisi, modelden elde edilen hata terimleri arasındaki ilişkiyi ifade eden otokorelasyon sorunu; diğeri ise hata terimleri varyansının zaman içerisinde sabit olmamasını ifade eden değişen varyans sorunudur (Aharon ve Qadan, 2019: 57; Apolinario vd., 2006: 57). Çalışmada değişen varyans sorunu çözmek için Nelson (1991) tarafından geliştirilen EGARCH(p,q) modeli uygulanmıştır. $\operatorname{EGARCH}(\mathrm{p}, \mathrm{q})$ modeli aşağıdaki gibi ifade edilmektedir:

$$
\log \left(\sigma_{\mathrm{t}}^{2}\right)=\alpha_{0}+\sum_{\mathrm{i}=1}^{\mathrm{q}} \alpha_{\mathrm{i}} \frac{\left|\varepsilon_{\mathrm{t}-\mathrm{i}}\right|}{\sigma_{\mathrm{t}-\mathrm{j}}}+\sum_{\mathrm{i}=1}^{\mathrm{q}} \gamma_{\mathrm{i}} \frac{\varepsilon_{\mathrm{t}-\mathrm{i}}}{\sigma_{\mathrm{t}-\mathrm{i}}}+\sum_{j=1}^{p} \beta_{\mathrm{j}} \log \left(\sigma_{\mathrm{t}-\mathrm{j}}^{2}\right)
$$

Yukarıdaki eşitlikte, ot2 koşullu varyansı; ct, sıfır ortalamalı ve sabit varyanslı hata terimini; $\mathrm{q}$, hata karelerinin gecikme uzunluğunu; $\mathrm{p}$, koşullu varyansın gecikme uzunluğunu; $\alpha \mathrm{i}$ ve $\beta \mathrm{j}$ sırasıyla koşullu varyans üzerindeki ARCH ve GARCH etkilerini; $\alpha 0$ katsayısı, koşullu varyans denkleminin sabit değerlerini; $\gamma$ parametresi ise asimetrik etkiyi simgelemektedir.

\section{BULGULAR}

Çalışmada kullanılan Bitcoin getiri serilerine ilişkin tanımlayıcı istatistikler Tablo 1'de yer almaktadır. Tablo 1 incelendiğinde, örneklem döneminde serinin ortalama getirisinin negatif olduğu, serilerin sağa çarpık ve aşırı basık bir dağılım gösterdiği sonucuna varılmaktadır. Bu durum serilerin normal dağılım göstermediğini ifade etmektedir. Ayrıca Jarque-Bera test istatistiği serilerin normal dağılım göstermediğini desteklemektedir. 
Tablo 1. Bitcoin Getiri Serisine İlișkin Tanımlayıcı İstatistikler

\begin{tabular}{|l|c|}
\hline & Bitcoin \\
\hline Ortalama & -0.001666 \\
\hline Medyan & -0.001844 \\
\hline Maksimum & 0.266198 \\
\hline Minimum & -0.357451 \\
\hline Standart Sapma & 0.042930 \\
\hline Çarpiklık & 0.158045 \\
\hline Basıklık & 10.65866 \\
\hline Jarque-Bera & 5873.048 \\
(Prob) & 0.000000 \\
\hline
\end{tabular}

Haftanın günü anomalisini test eden doğru bir model oluşturabilmek için getiri serilerinin durağanlığının kontrol edilmesi gerekmektedir. Bu nedenle çalışmada Augemented Dickey Fuller (ADF) ve Phillips-Peron (PP) birim kök testleri uygulanmış ve sabit terimli, sabit terimli ve trendli modeller oluşturulmuştur. Birim kök test sonuçlarının yer aldığı Tablo 2'ye göre getiri serisinin birim köke sahip olduğu şeklinde kurulan sıfır hipotezi \%1 anlamlılık düzeyinde reddedilmektedir. Bu kapsamda serilerin düzey değerlerinde durağan olduğu ve birim kök içermediğini sonucuna ulaşılmıştır.

Tablo 2. Bitcoin Getiri Serisine İlişkin Birim Kök Test Sonuçları

\begin{tabular}{|l|l|l|l|}
\hline \multicolumn{2}{|c|}{ ADF } & \multicolumn{2}{c|}{ PP } \\
\hline Sabit Terimli & Sabit Terimli ve Trendli & Sabit Terimli & $\begin{array}{l}\text { Sabit Terimli ve } \\
\text { Trendli }\end{array}$ \\
\hline$-48.83136(0.000)$ & $-48.82205(0.000)$ & $-48.98891(0.000)$ & $-48.97991(0.000)$ \\
\hline $\begin{array}{l}\text { ADF testi için gecikme sayısının belirlenmesinde SIC bilgi kriteri kullanılmıştır. PP testi için } \\
\text { Barlett kernel fonksiyonu ve bant genişliği için Newey-West yöntemi kullanılmıştır. Parantez } \\
\text { içindeki değerler olasılık değerlerini göstermektedir. }\end{array}$ \\
\hline
\end{tabular}

Tablo 3'de yer alan Breusch-Godfrey LM test sonuçları Bitcoin getiri serilerinde otokorelasyon sorunu olmadığını gösterirken, ARCH-LM test sonuçları getiri serilerinde ARCH etkisinin varlığını yani değişen varyans sorununun olduğunu ortaya koymaktadır. Bouoiyour ve Selmi (2015) ile Uzkaralar ve Evci (2018) çalışmalarında Bitcoin fiyat serilerinde asimetrik etkinin varlığını gözlemlemişlerdir. Bu kapsamda çalışmada, değişen varyans sorununu çözmek için EGARCH modelleri üzerinden Bitcoin getiri serileri modellenmiştir.

Tablo 3. Bitcoin Getiri Serisine İlişkin Otokorelasyon ve Değişen Varyans Test Sonuçları

\begin{tabular}{|c|c|c|}
\hline & $\mathbf{n R}^{2}$ & Olasılık değeri (p) \\
\hline Breusch- Godfrey LM Testi & $8.0856 *$ & 0.1516 \\
\hline ARCH-LM (1) & 217.3697 & 0.0000 \\
\hline ARCH-LM (7) & 280.1164 & 0.0000 \\
\hline \multicolumn{3}{|c|}{$\begin{array}{c}\text { ARCH-LM(1) ve ARCH-LM(7) sirasıyla 1. ve 7. gecikmedeki değerleri } \\
\text { ifade etmektedir. }\end{array}$} \\
\hline
\end{tabular}

Üç gecikme uzunluğu dikkate alınarak oluşturulan EGARCH modelleri arasında en uygun olanı, parametrelerin anlamlı ve $\beta$ parametresi toplamlarının birden küçük olması, Akaike (AIC) ve Schwarz (SIC) bilgi kriterlerinin küçük olması koşulları esas alınarak belirlenmiştir. $\mathrm{Bu}$ bağlamda en uygun modelin EGARCH $(2,1,1)$ modeli olduğu tespit edilmiştir. Oluşturulan modele kukla değişkenler eklenerek, Bitcoin getiri serisinde haftanın günü anomalisi test edilmiş ve sonuçlar Tablo 4'de sunulmuştur. 
Tablo 4. Bitcoin Getiri Serisine İlişskin Model Tahmin Sonuçları

\begin{tabular}{|c|c|c|}
\hline Günler & Katsayı & Standart Hata \\
\hline Pazartesi & $-0.005808(0.002)$ & 0.001879 \\
\hline Salı & $0.000982(0.622)$ & 0.001995 \\
\hline Çarşamba & $0.000671(0.643)$ & 0.001450 \\
\hline Perşembe & $-0.006011(0.001)$ & 0.001856 \\
\hline Cuma & $-0.002670(0.207)$ & 0.002118 \\
\hline Cumartesi & $-0.002173(0.242)$ & 0.001858 \\
\hline Pazar & $-0.003451(0.055)$ & 0.001803 \\
\hline \multicolumn{3}{|c|}{ Koşullu Varyans Denklemi } \\
\hline & EGARCH(2,1,1) & Standart Hata \\
\hline$\alpha_{0}$ & $-0.785422(0.000)$ & 0.064237 \\
\hline$\alpha_{1}$ & $0.469948(0.000)$ & 0.029682 \\
\hline$\gamma_{1}$ & $-0.094366(0.000)$ & 0.015902 \\
\hline$\beta_{1}$ & $0.704641(0.000)$ & 0.072569 \\
\hline $\mathbf{B}_{2}$ & $0.226664(0.001)$ & 0.069785 \\
\hline AIC & \multicolumn{2}{|c|}{-3.864932} \\
\hline SIC & \multicolumn{2}{|c|}{-3.836006} \\
\hline ARCH-LM(1) & \multicolumn{2}{|c|}{$1.287270(0.256)$} \\
\hline ARCH-LM(7) & \multicolumn{2}{|c|}{$4.094718(0.7688)$} \\
\hline
\end{tabular}

Tablo 4'de yer alan sonuçlara göre Pazartesi ve Perşembe günlerinin kukla değişkenleri \%1, Pazar gününün kukla değişkeni ise \%10 önem düzeyinde istatistiki açıdan anlamlıdır. Pazartesi, Perşembe ve Pazar günlerinin katsayılarının anlamlı ve negatif olması, bu günlerde Bitcoin'in ortalama getirisinin değiştiğini, Pazartesi ve Perşembe günlerindeki kayıpların Pazar gününe göre daha fazla olduğunu ortaya koymaktadır. Diğer günlere ait kukla değişkenlerinin anlamsız olması nedeniyle haftanın günü etkisine rastlanılmamıştır. Bunun yanı sıra ARCH-LM test sonuçlarına göre değişen varyans sorunu ortadan kalkmıştır. Modelin tahmin edilmesinde kullanılan asimetrik $\operatorname{EGARCH}(2,1,1)$ modelindeki $\gamma$ parametresi istatistiki açıdan anlamlı ve negatif olması, getiri serilerinde asimetrik etkinin varlığını ortaya koymakta ve olumsuz haberlerin olumlu haberlere göre daha fazla oynaklığa neden olduğunu göstermektedir.

\section{SONUÇ}

Kripto para piyasası kısa dönemde çok hızlı bir gelişim göstermiş hem yatırımcıların hem de akademisyenlerin ilgisini çekmiştir. 500'den fazla kripto para biriminin yer aldığı piyasada en fazla işlem hacmine sahip olanı Bitcoin'dir. Gerek geleneksel finansal piyasaların işleyişinden farklı bir piyasa işleyişine sahip olması gerekse para yaratma sürecinde farklı bir sistemi kullanması yatırımcılar açısından Bitcoin fiyatlarında değişime yol açan faktörleri 
anlamayı gerekli kılmaktadır. Bu çalışma ile Bitcoin fiyatlarında haftanın günü anomalisinin varlığının araştırılması amaçlanmaktadır.

Çalışmada haftanın günü anomalisi 28.04.2013-22.11.2019 tarihleri arasındaki günlük fiyatlar kullanılarak, asimetrik GARCH modelleri arasında yer alan EGARCH modeliyle araştırılmıştır. Bu bağlamda çalışmada ilk olarak getiri serilerin durağanlığı ADF ve PP birim kök testleriyle incelenmiş ve serilerin durağan olduğu sonucuna varılmıştır. Ardından serilere uygulanan Breusch-Godfrey LM test sonuçları Bitcoin getiri serilerinde otokorelasyon sorunu olmadığını göstermiş, ARCH-LM test sonuçları ise getiri serilerinde ARCH etkisinin varlığını yani değişen varyans sorununun olduğunu ortaya koymuştur. Değişen varyans sorununu çözmek amacıyla EGARCH(2,1,1) modeli kullanılmış ve oluşturulan modele kukla değişkenler eklenerek haftanın günü anomalisi incelenmiştir. Model tahmin sonuçları, Pazartesi ve Perşembe günlerinin kukla değişkenlerinin \%1, Pazar gününün kukla değişkeninin ise \%10 önem düzeyinde istatistiki açıdan anlamlı ve negatif olduğunu ortaya koymuştur. Bu durum Pazartesi, Perşembe ve Pazar günleri Bitcoin'in ortalama getirisinin değiştiğini; bu günlere ait parametre katsayıları da Pazartesi ve Perşembe günlerindeki kayıpların Pazar gününe göre daha fazla olduğunu göstermiştir.

Bitcoin piyasasında haftanın günü anomalisinin varlığı, Etkin Piyasa Hipotezinden sapan fiyat oluşumlarının bu piyasada gözlemlendiğini ve piyasasının etkin olmadığını açıklamaktadır. Buna göre Bitcoin piyasasında geçmiş dönem fiyat hareketleri kullanılarak geleceğe yönelik öngörülerde bulunabilinecektir. Bitcoin piyasasında getirilerin belirli günlerde farklılık göstermesi yatırımcıların bu günlerde ortalama getirinin üzerinde ya da altında getiri elde etmesine neden olmaktadır. Yatırımcının bu günlerin getiriler üzerindeki etkisini doğru şekilde tahmin etmesi ve buna uygun yatırım stratejilerini belirlemesi halinde piyasa ortalamasının üzerinde getiri elde etmesi ve riskini yönetmesi mümkün olabilecektir.

\section{KAYNAKÇA}

AGGARWAL, R. ve RIVOLİ, P. (1989). "Seasonal and Day-of-The-Week Effects in Four Emerging Stock Markets", Financial Review, 24(4): 541-550.

AHARON, D. Y. ve QADAN, M. (2018). "Bitcoin and Day-of-The-Week Effect”, Finance Research Letters. 31.

APOLINARIO, R. M. C., SANTANA, O. M., SALES, L. J.ve CARO, A. R. (2006). "Day of The Week Effect on European Stock Markets", International Research Journal of Finance and Economics, 2(1): 53-70.

ARI, A., ve YÜKSEL, Ö. (2017). "BİST 100'de Haftanın Günü Anomalisi: Ekonometrik Bir Analiz”, Finans Politik \& Ekonomik Yorumlar, 54(632): 77-89.

BARIVIERA A. F., BASGALL M. J., HASPERUe' W. ve NAIOUF, M. (2017). "Some Stylized Facts of the Bitcoin Market", Physica A:Statistical Mechanics and its Applications. 2017; 484: 82-90.

BOUCHAUD J. P., POTTERS, M. (2003). Theory of Financial Risk And Derivative Pricing: From Statistical Physics To Risk Management, Cambridge University Press.

BOUOIYOUR, J. ve SELMI, R. (2015). "What Does Bitcoin Look Like?", Annals of Economics \& Finance, (2): 16. 
BROOKS, C. ve PERSAND, G. (2001). "Seasonality in Southeast Asian Stock Markets: Some New Evidence on Day-Of-The-Week Effects", Applied Economics Letters, 8(3): $155-158$.

CAPORAlE, G. M., ve PLASTUN, A. (2019). "The Day of the Week Effect in the Cryptocurrency Market”, Finance Research Letters, 31: 258-269.

Coinmarketcap, https://coinmarketcap.com/charts, 25.09.2019

EYÜBOĞLU, K. (2018). "Examining Day Of the Week and Month Of The Year Effects in Bitcoin and Litecoin Markets”, Çankırı Karatekin Üniversitesi İIBF Dergisi, 8(1): 165 183.

Fama, E. F. (1965). The behaviour of stock market prices. Journal of Business, 38(10): 34105 .

FAMA, E. F., (1970). Efficient Capital Markets: A Review Of Theory And Empirical Work", Journal of Finance, 25: 338-417.

FARELL, R. (2015). “An Analysis Of The Cryptocurrency Industry”, Wharton Research Scholars. 130: 1-23

FINK, C. ve JOHANN, T. (2014). "Bitcoin Markets", https://papers.ssrn.com/sol3/papers.cfm?abstract_id=2408396, 15.09.2019.

FRENNBERG, P. ve HANSSON, B. (1993). "Testing The Random Walk Hypothesis On Swedish Stock Prices: 1919-1990”, Journal of Banking \& Finance, 17(1): 175-191

GÜLTEKİN, Y. ve BULUT, Y. (2016). "Bitcoin Ekonomisi: Bitcoin Eko-Sisteminden Doğan Yeni Sektörler ve Analizi”, Adnan Menderes Üniversitesi, Sosyal Bilimler Enstitüsü Dergisi, 3(3): 82-92.

JANG, H. ve LEE, J. (2017). “An Empirical Study On Modeling And Prediction Of Bitcoin Prices With Bayesian Neural Networks Based On Blockchain Information”, IEEE Access: 5427-5437.

JIANG Y, NIE H. ve RUAN W. (2018). “Time-Varying Long-Term Memory in Bitcoin Market”, Finance Research Letters. 25: 280-284.

KOÇOĞLU, Ş., ÇEVİK, Y. E. ve TANRIÖVEN, C. (2016). "Bitcoin Piyasalarının Etkinliği, Likiditesi ve Oynaklığı”, İşletme Araştırmaları Dergisi, 8 (2): 77-97.

KRISTOUFEK, L. (2015). "What Are The Main Drivers Of The Bitcoin Price? Evidence from Wavelet Coherence Analysis", PloS one, 10(4): 1-15.

KUMAR, S. (2016). "Revisiting Calendar Anomalies: Three Decades Of Multicurrency Evidence", Journal of Economics and Business, 86:16-32.

KURIHARA Y. ve FUKUSHIMA, A. (2017). "The Market Efficiency Of Bitcoin: A Weekly Anomaly Perspective", Journal of Applied Finance \& Banking, 7(3): 57-64.

KURIHARA, Y. (2011). "Is The Tokyo Foreign Exchange Market Efficient From Two Perspectives Of Forward Bias And Anomaly?”, Modern Economy, 2(4): 597-601. 
LAHMIRI, S., BEKIROS, S., ve SALVI, A.(2018). "Long-Range Memory, Distributional Variation and Randomness Of Bitcoin Volatility", Chaos, Solitons \& Fractals. 107:43-48.

MUKHOPADHYAY, U., SKJELLUM, A., HAMBOLU, O., OAKLEY, J., YU, L., ve BROOKS, R.R. (2016). "A Brief Survey of Cryptocurrency Systems”, In Proceedings of 14th Annual Conference on Privacy, Security and Trust: 745-752.

NAKAMOTO, S., (2008). "Bitcoin: A Peer to Peer Electronic Cash System". http://bitcoin.org/bitcoin.pdf, 2008, 01.10.2019.

NELSON, D., B. (1991). "Conditional Heteroskedasticity in Asset Returns: A New Approach”, Econometrica, 59: 347-70.

OSTERRIEDER J. ve LORENZ J.(2017). “A Statistical Risk Assessment of Bitcoin and Its Extreme Tail Behavior”, Annals of Financial Economics. 2017; 12(01):1750003

POPOVIĆ, S. ve ĐUROVIĆ, A. (2014). "Intraweek and Intraday Trade Anomalies: Evidence from Forex Market”, Applied Economics, 46(32): 3968-3979.

RODRIGUEZ, W. K. (2012). "Day of the Week Effect in Latin American Stock Markets", Journal of Economic Analysis, 27: 71-89.

SHI F-B, SUN X-Q, GAO J-H, XU L, SHEN H-W ve CHENG X-Q (2019). “Anomaly Detection in Bitcoin Market via Price Return Analysis", PLoS ONE 14(6): 1-11.

SMITH, G. ve RYOO H.J. (2003). "Variance Ratio Tests of the Random Walk Hypothesis for European Emerging Stock Markets”, European Journal of Finance, 9(3): 290-300.

Tradingview, https://tr.tradingview.com. 25.09.2019.

UZKARALAR, Ö. ve EVCI, S.(2018). "Kripto Para Piyasasında Asimetrik Etkinin İncelenmesi”, Akça, H.(Der), I.Uluslararası Multidisipliner Çalışmaları Kongresi içinde (37-46). Ankara:Akademisyen Kitabevi

WORTHINGTON, A. ve HIGGS, H. (2003). "Random Walks and Market Efficiency in European Equity Markets", Global Journal of Finance and Economics, 1 (1): 59-78.

YAMORI, N.ve KURIHARA, Y. (2004). "The day-of-the-Week Effect in Foreign Exchange Markets: Multi-Currency Evidence", Research in International Business and Finance, 18(1): 51-57. 